\title{
INFORMAÇÃO E EDUCAÇÃO NO ENSINO SUPERIOR
}

\author{
INFORMATION AND EDUCATION IN HIGHER EDUCATION
}

\author{
Lilian Viana \\ Ivete Pieruccini
}

\begin{abstract}
Resumo: No cenário informacional contemporâneo as perspectivas de acesso avolumam-se, mas, por outro lado, a construção de significações torna-se cada vez mais complexa num mundo em que a informação parece ter sido colocada como valor acima do conhecimento. $\mathrm{O}$ ensino superior é espaço privilegiado à construção do conhecimento, instância capaz de promover mudanças sociais na medida em que considera o saber sob o prisma do direito do cidadão. Questionar sobre a educação para a informação no ensino superior implica compreender se há condições de possibilidade para o desenvolvimento de ações que coloquem o sujeito em relações dialógicas com o conhecimento. A pesquisa em causa, a ser desenvolvida a partir da abordagem da Infoeducação, propõe-se a estabelecer proposições teórico-metodológicas que possam contribuir para o desenvolvimento de ações infoeducativas no ensino superior, portanto, considerando as dinâmicas de apropriação dos saberes informacionais pelos sujeitos, levando em conta suas dimensões individual e social, subjetiva e objetiva, intersubjetiva e relacional.
\end{abstract}

Palavras-chave: Infoeducação, Informação e Educação, Ensino superior.

Abstract: In the contemporary informational scene access perspectives increase, but, on the other hand, the construction of meanings becomes increasingly complex in a world in which information seems to have been placed above the knowledge. Higher education is a privileged space for the construction of knowledge, it is capable of promoting social change insofar as it considers knowledge under the prism of citizen's right. Call into question education for information in higher education implies understanding if there are conditions of possibility for the development of actions that place individuals in dialogic relations with knowledge. The research aims to establish theoreticalmethodological propositions that can contribute to the development of the library instruction and construction of meaning for the use of the informational/cultural center in higher education, therefore, considering the dynamics of construction of knowledge by individuals, taking into account their individual and social dimensions, subjective and objective, intersubjective and relational.

Keywords: Infoeducation, Information and Education, Higher education.

\section{Introdução}

$\mathrm{Na}$ assim chamada Sociedade da Informação, cada vez mais, as relações que os sujeitos estabelecem com a informação determinam suas vidas bem como sua participação no mundo. Dizer isto, descortina, de imediato, duas possibilidades: uma delas, que o homem acabe sendo simplesmente definido pelos contextos em que vive, o que implicaria, neste caso, a preponderância da técnica sobre o ser humano. Outra possibilidade: o homem como sujeito afirmativo de seu tempo, definindo rumos e não apenas sendo definido pelo contexto em que está inserido. O sucesso desta segunda perspectiva coloca-nos perante a complexidade do atual cenário, marcado pelo excesso informacional, o qual demanda o desenvolvimento de 
Seminário de Pesquisa em Ciência da Informação do PPGCI 2017

Escola de Comunicações e Artes - Universidade de São Paulo

saberes que propiciem o relacionamento dos sujeitos com a informação em perspectiva crítica e criativa.

O desenvolvimento de saberes informacionais é inalienável à construção do conhecimento, pois como ilustra a metáfora de Lévi-Strauss a informação seria aquilo que é cru, enquanto o conhecimento seria o cozido (BURKE, 2012, p.14). A referência ao cozimento compreende afirmar o conhecimento como sendo fruto da informação que é apropriada e, neste processo de cozer, são demandados determinados saberes.

A universidade é instituição privilegiada nos processos de construção do conhecimento. Entretanto, seu potencial gerador de conhecimento pode ser comprometido caso não se lance em busca de alternativas para a construção de programas com o foco no desenvolvimento de saberes informacionais que compreendam o complexo quadro contemporâneo, tendo em vista ultrapassar visões reducionistas e tecnicistas focadas exclusivamente na organização e acesso informacional.

\section{Desenvolvimento}

A contemporaneidade é marcada por profundas transformações operadas pelo avanço das tecnologias de informação e comunicação inseridas num contexto de globalização do qual também fazem parte como agentes da compressão espaço-temporal, conforme assinala Harvey (2002). A ênfase contemporânea na informação, em estar informado encaminha a sociedade para minimização de possibilidades de construção de experiências significativas com a informação. Conforme sinalizou Larossa Bondía (2002), o sujeito da informação empreende seu tempo em buscas informacionais, preocupado com não ter bastante informação. Em meio a tantas informações não temos tempo para processá-las, somos então induzidos a fazer um uso meramente instrumental do repertório informacional que coletamos. Em face disso, somos seres da significação à deriva em um mar de signos e, mais do que nunca, precisamos de bússolas cognitivas para nos orientarmos.

$\mathrm{O}$ ato de buscar informações não está dissociado do ato de aprender. A busca é, simultaneamente, causa e consequência da aprendizagem e, em meio à problemática da criação de significados e construção de conhecimentos, ressaltamos que o processo de busca informacional apresenta dimensão operatória bastante complexa, constituída de aspectos práticos, subjetivos e culturais (PIERUCCINI, 2004, p.33). Nesses termos, é fundamental considerar a importância do desenvolvimento de saberes informacionais, termo que define o conjunto complexo de habilidades, competências e atitudes indispensáveis não somente à sobrevivência individual e coletiva na sociedade da informação, mas para questionar a Revista Brasileira de Biblioteconomia e Documentação, São Paulo, v. 13, n. esp., p. 41-45, set. 2017. 
Seminário de Pesquisa em Ciência da Informação do PPGCI 2017

Escola de Comunicações e Artes - Universidade de São Paulo

informação, em seus princípios, dinâmicas e processos. Se compreendemos que a informação constitui uma ordem do conhecimento, e que esta, muitas vezes nubla outras tantas possibilidades de compreensão do real, a noção de saberes informacionais passa à dimensão essencial, como categoria inalienável aos processos de construção de significados por parte dos sujeitos (PERROTTI; PIERUCCINI, 2012, p. 6).

$\mathrm{O}$ ensino superior é espaço privilegiado ao desenvolvimento de novos conhecimentos nos domínios tecnológicos, culturais, econômicos e sociais, podendo contribuir para melhorias e avanços sociais. A construção da autonomia dos estudantes para caminhar nesta direção implica projeto político que considere a educação como investimento social. Especificamente no contexto brasileiro, alertamos para uma problemática no âmbito do ensino superior público, que tende a ser tratado pelo estado como um serviço, privilégio de poucos, sendo a universidade cada vez mais encarada a partir do prisma organizacional. Critérios de êxito e eficácia passam a definir as referidas instituições de ensino superior como organizações que "vivem de seu meio e não para seu meio" (SILVA, 1999, p. 40), o que equivale dizer, portanto, que sua destinação pública é anulada, sobrepondo-se a esta, o utilitarismo do atendimento a demandas emanadas por esferas que pretendem instrumentalizar o conhecimento à ordem econômica.

Descortina-se, assim, um complexo quadro que envolve os saberes informacionais no âmbito do ensino superior, já que é também necessária a criação de condições de possibilidade para que se consolidem como uma prática efetiva, transformando a busca e apropriação de informação em atos de significação (BRUNER, 1997), isto é, ancoradas em perspectiva crítica e afirmativa, condição vital o aos processos de conhecer o conhecimento.

A problemática culminou na pesquisa em causa, que tem sua relevância social na medida em que propõe discutir a questão dos saberes informacionais no ensino superior, com vistas ao estabelecimento de proposições neste domínio. $\mathrm{O}$ estudo, certamente enseja questões de diferentes ordens tais como as ações específicas a serem desenvolvidas, observando-se, por exemplo, elementos como a busca informacional, gestão, tratamento, produção e publicação da informação; compreensão da dimensão político institucional aí implicada; as possibilidades de diálogo e cooperação entre os diferentes atores e instâncias envolvidos; os caminhos para concretização das ações; perfis profissionais para levar a cabo as ações, assim como outras questões que certamente irão se revelar ao longo do desenvolvimento da pesquisa. A ancoragem teórico-metodológica do trabalho parte da abordagem da Infoeducação, considerada essencial na medida em que propõe conhecer as lógicas da informação e seus processos, bem como as dinâmicas de apropriação dos saberes informacionais pelos sujeitos, 
Seminário de Pesquisa em Ciência da Informação do PPGCI 2017

Escola de Comunicações e Artes - Universidade de São Paulo

levando em conta suas dimensões individual e social, subjetiva e objetiva, intersubjetiva e relacional.

\section{Conclusão}

A pesquisa em causa compreende análise e reflexão acerca de processos implicados no desenvolvimento de ações infoeducativas no âmbito do ensino superior. Perante a importância do ensino superior na formação de quadros capazes de protagonizar o conhecimento, estão em discussão proposições teórico-metodológicas que contribuam aos processos de apropriação da informação e cultura pelos sujeitos. Diante disto, vale dizer que é premente considerarmos os paradigmas que ditam os rumos da educação superior em nosso país, pois isto contribuirá para compreendermos as relações estabelecidas com o conhecimento: Conhecimento para quê? Conhecimento para quem?

A pesquisa pretende se ocupar de questões inerentes aos processos de busca, seleção, organização, apropriação e uso da informação, considerado o contexto informacional contemporâneo. Muito além de uma perspectiva meramente instrumental sobre usos competentes da informação, coloca-se em pauta as atitudes dos sujeitos face ao universo informacional e à construção do conhecimento. Com isso pretendemos buscar caminhos para ensinar a informação para além de procedimentos de uso, tendo em vista um público que, muitas vezes, já chega às bibliotecas inundado de informações, mas, simultaneamente, necessitando de outras. Encarar tais questões é essencial para que possamos caminhar em busca da construção de saberes informacionais, já que conhecer o conhecimento é fundamental para superar as cegueiras, os erros e ilusões (MORIN, 2002) inerentes a sua ordem. Protagonizar nossa sociedade, nossa história, implica protagonistas culturais, posição a ser construída, tendo em vista ultrapassar a condição de meros consumidores competentes de informações, limitados a reproduzir conhecimentos já consagrados. A importância social da pesquisa é então realçada na medida em que pretende contribuir para a formação de sujeitos críticos e criativos em suas relações com o conhecimento, perspectiva essencial ao desenvolvimento de uma sociedade que encara o saber sob o prisma do direito à cidadania cultural.

\section{Referências}

BRUNER, Jeromê. Atos de significação. Porto Alegre: Artmed, 1997.

BURKE, Peter. Uma história social do conhecimento II: da Enciclopédia a Wikipédia. Rio de Janeiro: Zahar, 2012. 
HARVEY, David. Condição pós-moderna. São Paulo: Loyola, 2002.

LAROSSA BONDIA, Jorge. Notas sobre a experiência e o saber de experiência. Revista Brasileira de Educação, n. 19, p.20-28, jan/abr 2002.

MORIN, Edgar. Os sete saberes necessários à educação do futuro. 6.ed. São Paulo: Cortez, 2002.

PERROTTI, Edmir; PIERUCCINI, Ivete. Infoeducação: um salto para o futuro.(mensagem pessoal. Artigo em formato pdf). Mensagem recebida por: < lilianviana@usp.br> em ago. 2012.

PIERUCCINI, Ivete. A ordem informacional dialógica: estudo sobre a busca de informação em educação. 2004. Tese (Doutorado em Ciência da Informação) - Escola de Comunicações e Artes, Universidade de São Paulo, São Paulo, 2004.

SILVA, Franklin Leopoldo e. A experiência universitária entre dois liberalismos. Tempo social, Rev. Sociol. USP, São Paulo, v.11 n.1, p.1-47, maio 1999.

\section{Sobre as autoras}

\section{Lilian Viana}

Doutoranda no PPGCI-ECA-USP.1ilianviana@usp.br

Bibliotecária na Escola de Comunicações e Artes da Universidade de São Paulo.

Ivete Pieruccini

Professora Doutora na Escola de Comunicações e Artes da Universidade de São Paulo. ivetepie@usp.br 